\title{
Pemanfaatan Media Website sebagai Promosi Penjualan Alat Pancing Muara Pancing Disaat Pandemi Covid-19 di Kiringan RT 01/ RW 06 Boyolali
}

\author{
Irvan Rustam Muddin a,1,*, Sigit Muryanto ${ }^{\mathrm{b}, 2}$ \\ a Universitas Boyolali, Jl. Pandanaran No 405, Boyolali 57315, Indonesia \\ ${ }^{\mathrm{b}}$ Universitas Boyolali, J1. Pandanaran No 405, Boyolali 57315, Indonesia \\ ${ }^{1}$ irvanakiringan@gmail.com *; ${ }^{2}$ sigit.ms2013@gmail.com \\ * Koresponsendi penulis
}

\section{ARTICLE INFO}

Article history

Menerima 18 April 2021

Revisi 21 Juli 2021

Diterima 30 Juli 2021

Kata Kunci

Sistem Informasi

Website

Promosi Penjualan

\section{ABSTRACT}

The development of internet technology is currently experiencing a very rapid development, one of which is the website. In the era of the development of Information Technology as it is today, a system is needed that provides information to the general public by accessing websites on the internet. Currently marketing and pmotions are carried out by waiting for buyers to come directly to the store or word of mouth promotion (Word of Mouth). when the Covid 19 pandemic currently causes a decrease in turnover of Muara Pancing, therefore it is necessary to promote and deliver effective information, namely sales promotion at Muara Pancing "Muara Pancing MSME Web" which is expected to be the best solution, so that the fishing equipment MSME business can easily carry out promotions and make Muara Pancing known to the wider community so that many buyers come to Muara Pancing. To provide advice and assess the level of customer satisfaction a comment column is provided on the website, so that the owner can evaluate the advantages and disadvantages of the products being sold, in the end increase customer satisfaction and become regular customers, and bring to customers.

This is an open access article under the CC-BY-SA 4.0 license.

\section{Pendahuluan}

Muara Pancing merupakan UMKM yang menyediakan peralatan memancing,seperti, Joran, Senar, Reel, Aksesoris di Kiringan, Boyolali. Saat ini pemasaran dan promosi dilakukan dengan cara menunggu pembeli datang langsung ke toko atau promosi dari mulut ke mulut(Word of Mouth).Di saat Pandemi Covid 19 saat ini menyebabkan penurunan omzet Muara Pancing, maka dari itu diperlukan promosi dan penyampaian informasi yang efektif yaitu sarana promosi penjualan pada Muara Pancing "Web UMKM Muara Pancing" yang diharapkan menjadi solusi terbaik, agar usaha UMKM alat pancing dengan mudah melakukan promosi dan membuat Muara Pancing dikenal oleh masyarakat luas sehingga banyak pembeli datang ke Muara Pancing.Untuk memberikan saran dan menilai tingkat kepuasan pelanggan disediakan kolom komentar pada website,sehingga owner bisa mengevaluasi kelebihan dan kekurangan produk yang dijual, pada akhirnya meningkatkan kepuasan pelanggan dan menjadi pelanggan tetap,serta mendatangkan pelanggan-pelanggan baru.Kajian memakai website dalam promosi penjualan adalah pada saat situasi pandemi sekarang ini tidak di ijinkan adanya keramaian,biasanya promosi penjualan 
memakai brosur yang dibagikan,namun saya memilih media website agar tidak membuat kerumunan dan lebih menjangkau masyarakat luas,website dapat diakses siapa saja yang memiliki akses internet.

\section{Metode}

Metode yang digunakan antara lain Observasi merupakan langkah awal untuk mengetahui bagaimana memperoleh suatu informasi.Untuk mengetahui keadaan UMKM Muara Pancing, observasi dilakukan secara langsung dengan mendatangi Instansi Muara Pancing guna melakukan pengamatan dan wawancara untuk penyusunan program kerja KKN.

Pelaksanaan Program KKN ini dilakukan selama satu bulan yang dibagi dalam beberapa tahapan kegiatan. Pelaksanaan program KKN yang akan dilakukan adalah pembuatan stempel cap instansi, pembelian domain dan hosting website, pembuatan website.

Tahap pertama Observasi memerlukan waktu 4 (empat) hari di lokasi pengabdian. Tahap observasi adalah melakukan wawancara kepada Bapak Wiyarso selaku pemilik toko Alat Pancing Muara Pancing.Dalam pengamatan dan wawancara ini ditemukan masalah yaitu belum ada stempel instansi, stempel sangat penting dalam pengesahan dokumen maupun nota pembelian,masalah selanjutnya adalah ingin meningkatkan penjualan Muara Pancing,maka dari itu di buatlah website promosi yang telah disetujui owner.

Tahap kedua,pembuatan stempel,design stempel cap ini berisi nama Muara Pancing,alamat toko,gambar ikan nila.Pembuatan stampel ini dibuat oleh penjual stempel.

Tahap ketiga,pengambil foto produk Muara Pancing yang dilakukan oleh Irvan Rustam Muddin dan Bapak Wiyarso.

Tahap keempat,menentukan nama domain,hosting,serta menentukan item menu website promosi.Pada tahap ini dilakukan diskusi dengan Bapak Wiyarso selaku pemilik UMKM Muara Pancing.

\section{Hasil dan Pembahasan}

Website pembuat blog yang saya gunakan adalah wordpress. Word Press adalah perangkat lunak pembuat blog dan website yang paling mudah, paling popoler dan gratis untuk digunakan.WordPress juga terbukti mudah digunakan, bahkan oleh orang awam sekalipun.

\subsection{Peralatan}

Perangkat keras yang di gunakan untuk membangun sistem informasi kuliah kerja nyata di UMKM Muara Pancing ini adalah sebagai berikut :

1. Software / Perangkat Lunak : Web Browser (Google Chrome,Mozila Firefox).

2. Hardware / Perangkat Keras : Laptop dengan spesifikasi Processor Intel Celeron, Ram 4 GB, Hardisk 465,76 GB,Windows 1064 Bit.

\subsection{Bahan}

\section{A. Cpanel}

Menurut rujukan dari artikel https://www.domainesia.com/, Cpanel adalah sebuah control panel web hosting yang memberikan tampilan grafis dan peralatan automasi yang dibuat untuk memudahkan proses hosting di sebuah situs web[1]. Pada intinya, Cpanel merupakan suatu panel pengaturan utama pada hosting.

\section{B. Wordpress}

Menurut rujukan dari artikel https://www.niagahoster.co.id/. WordPress adalah perangkat lunak pembuat blog dan website yang paling mudah paling popoler dan gratis untuk 
digunakan [2].WordPress juga sangat mudah dipelajari. Selain itu WordPress juga terbukti mudah digunakan, bahkan oleh orang awam sekalipun.

\section{Web Browser}

Menurut rujukan dari artikel https://www.diadona.id/, Pengertian web browser adalah perangkat lunak untuk mengidentifikasi sumber informasi, yang berupa halaman website, gambar, video atau jenis konten lainnya. Fungsi Web Browser adalah mempermudah dalam pencarian informasi di internet,menyimpan berbgai data di internet,membuka file menggunakan ekstensi khusus,menjaga keamanan website,serta mendukung pemakaian search engine[3].

D. Alur Pembuatan Website

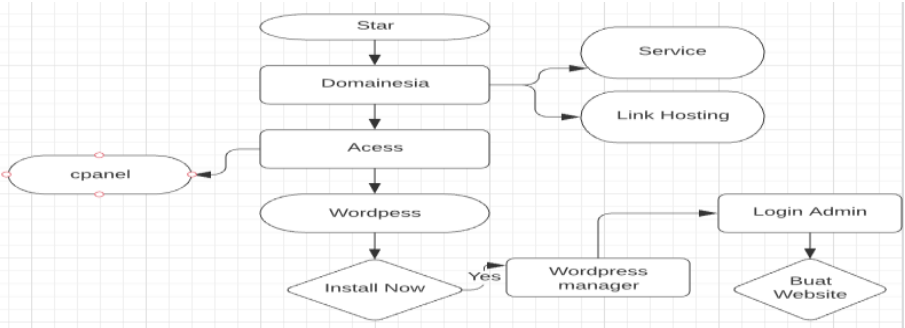

Fig. III 1. Alur Pembuatan Website

\subsection{Implementasi}

Menurut rujukan dari artikel https://saintif.com/, implementasi adalah penerapan atau pelaksanaan. Implementasi juga bisa diartikan sebagai tindakan untuk menjalankan rencana yang telah dibuat[4]. Pada tahapan implementasi dilakukan pembuatan dan Pemeliharaan sistem. Pembuatan Sistem dilakukan sesuai dengan data yang telah didapat melalui metode terkait.

Menu Website Muara Pancing :

a. Home

Merupakan tampilan website yang berisi profil Muara Pancing yaitu Gambaran Umum yang menampilkan informasi web secara singkat.

b. Jorans

Merupakan tampilan website yang berisi informasi produk joran berupa nama produk,harga,spesifikasi,Fungsi Joran adalah fasilitas untuk dudukan reel,tempat bertumpunya reel atau senar,hingga untuk mengarahkkan tarikan ikan.

c. Senar

Merupakan tampilan website yang berisi foto-foto produk yang dijual beserta nama produk,harga,spesifikasi.

d. Reel

Menurut rujukan dari artikel https://review.bukalapak.com/, Reel merupakan tampilan website yang berisi foto-foto produk yang dijual beserta nama produk,harga,spesifikasi. Rell berfungsi untuk menampung dan menggulung senar [5].

e. Aksesoris

Merupakan tampilan website yang berisi foto-foto produk yang dijual beserta nama produk,harga,spesifikasi.

f. Tentang Kami

Merupakan tampilan web yang berisi jam buka, nomor hp pemilik Muara Pancing . 


\subsection{Daftar Kegiatan}

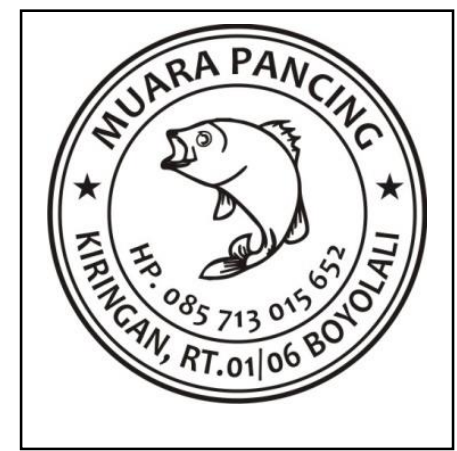

Fig. 1. (Pembuatan Design Muara Pancing )

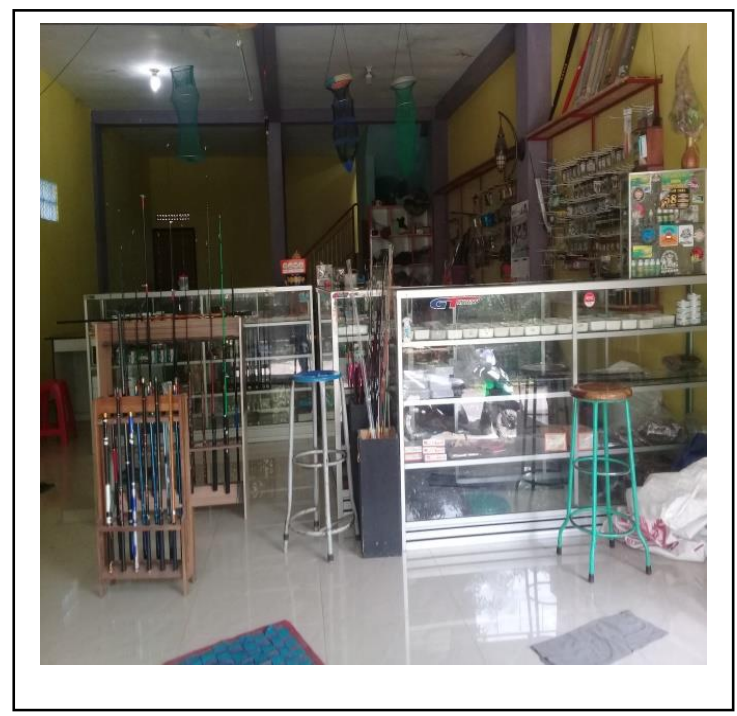

Fig. 2. ( Pengambilan Foto Produk Muara Pancing )

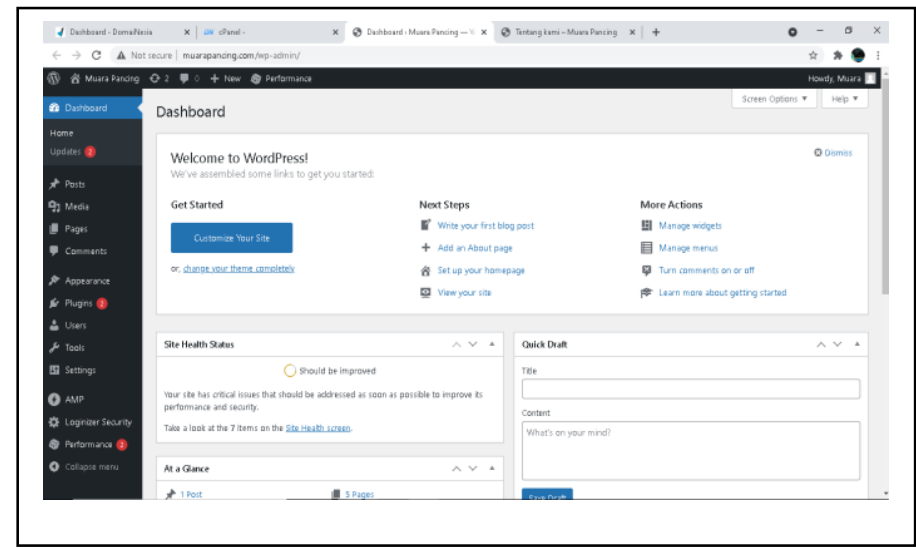

Fig 3. ( Memulai Pembuatan Website ) 


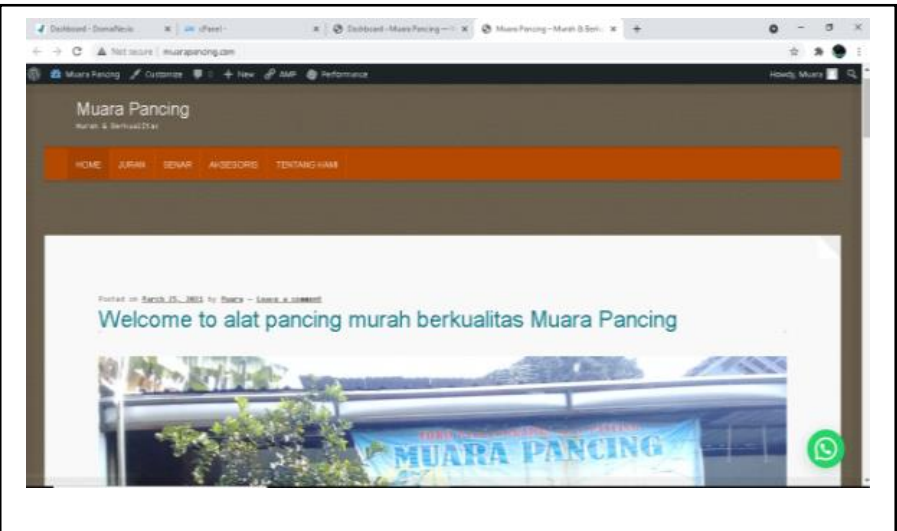

Fig. 4. ( Pembuatan Menu Home Website )

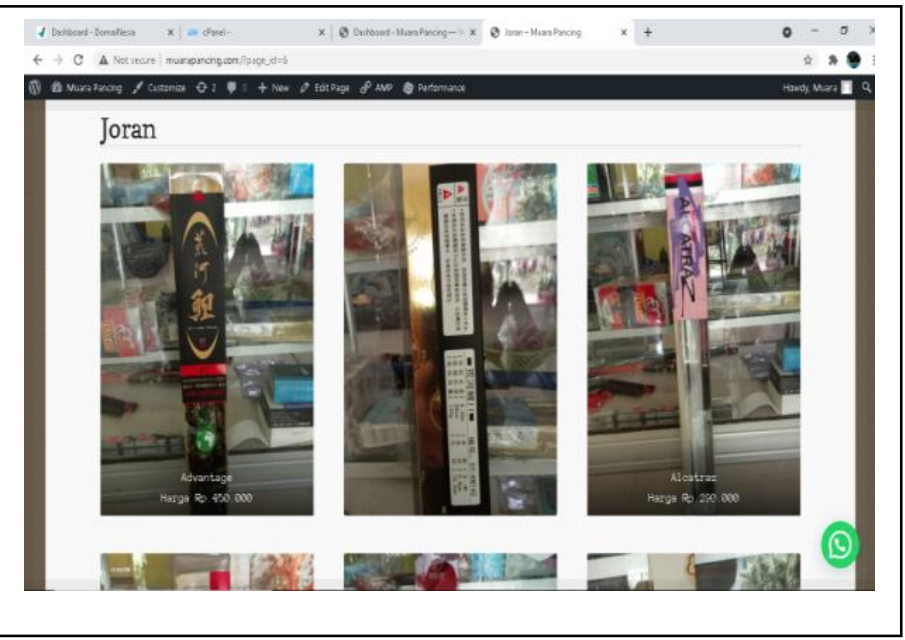

Fig. 5. ( Pembuatan Menu Joran )

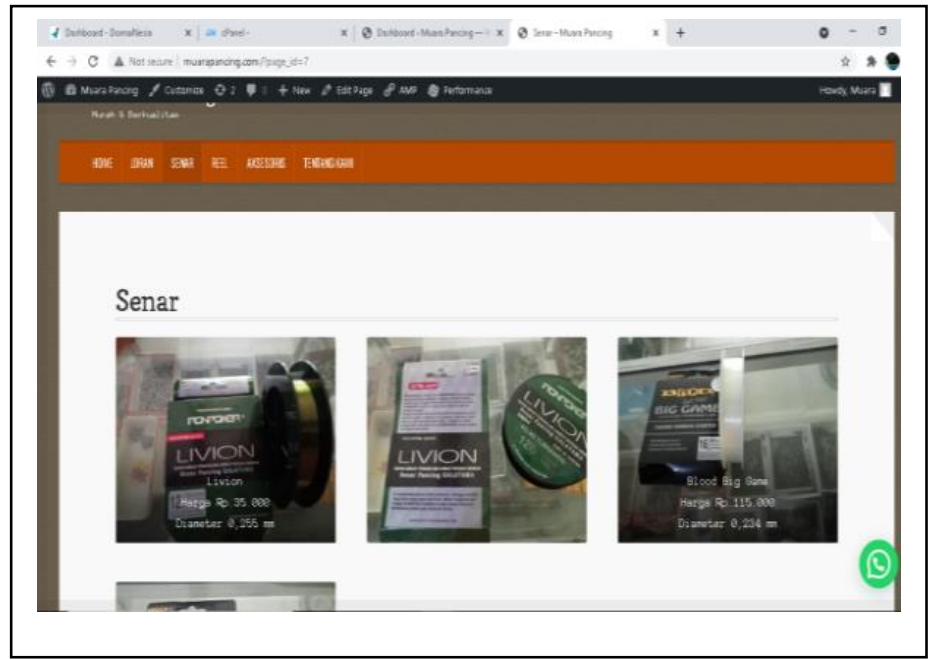

Fig. 6. ( Pembuatan Menu Senar ) 


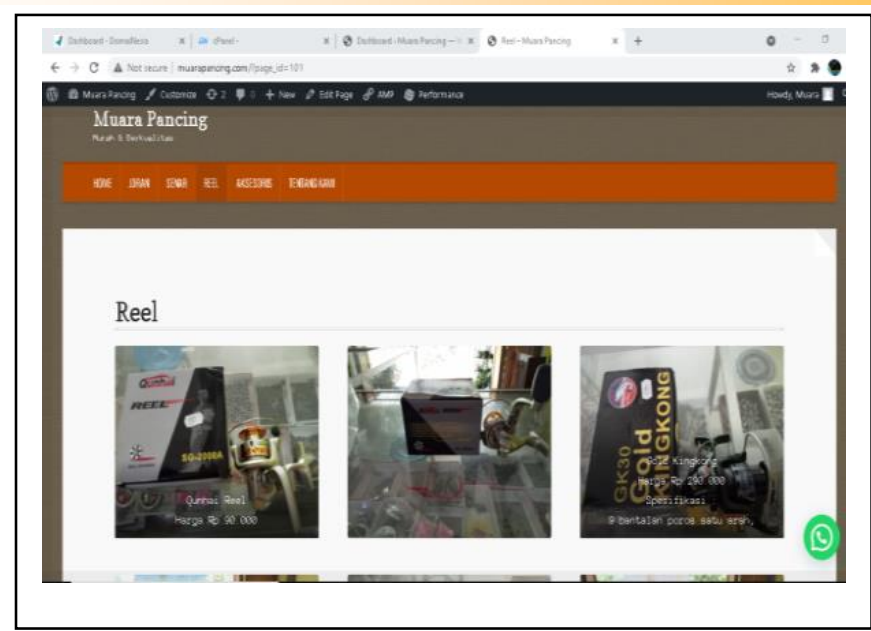

Fig. 7. ( Pembuatan Menu Reel )

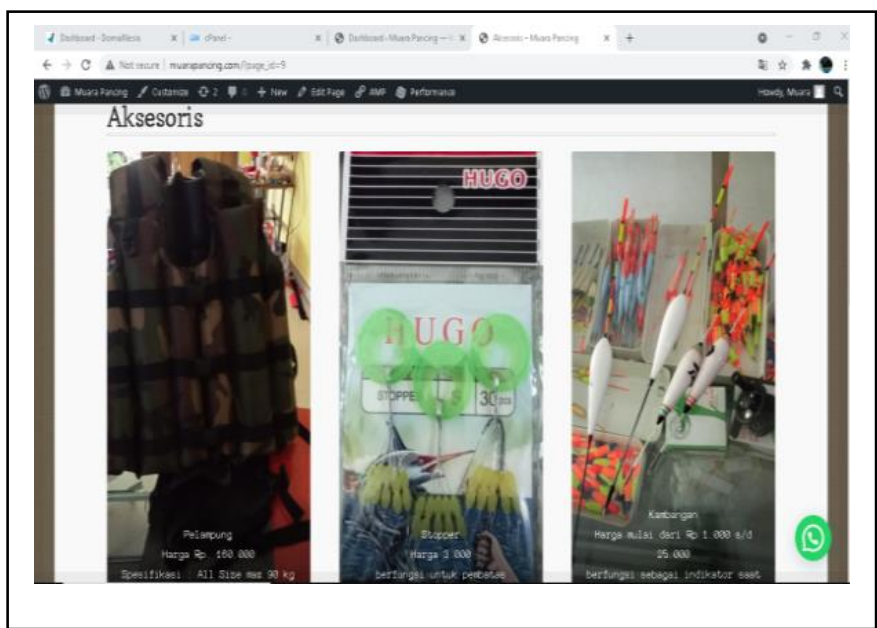

Fig. 8. ( Pembuatan Menu Aksesoris )

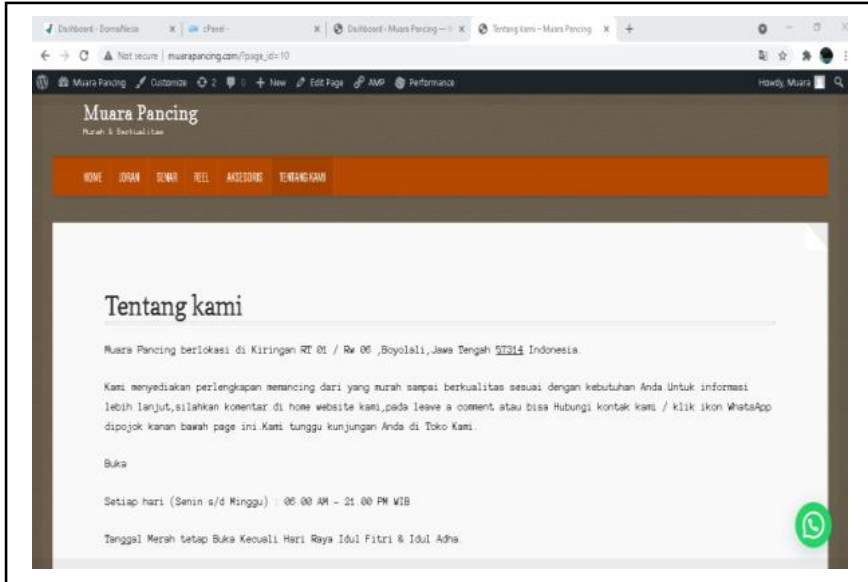

Fig. 9. ( Pembuatan Menu Tentang Kami ) 


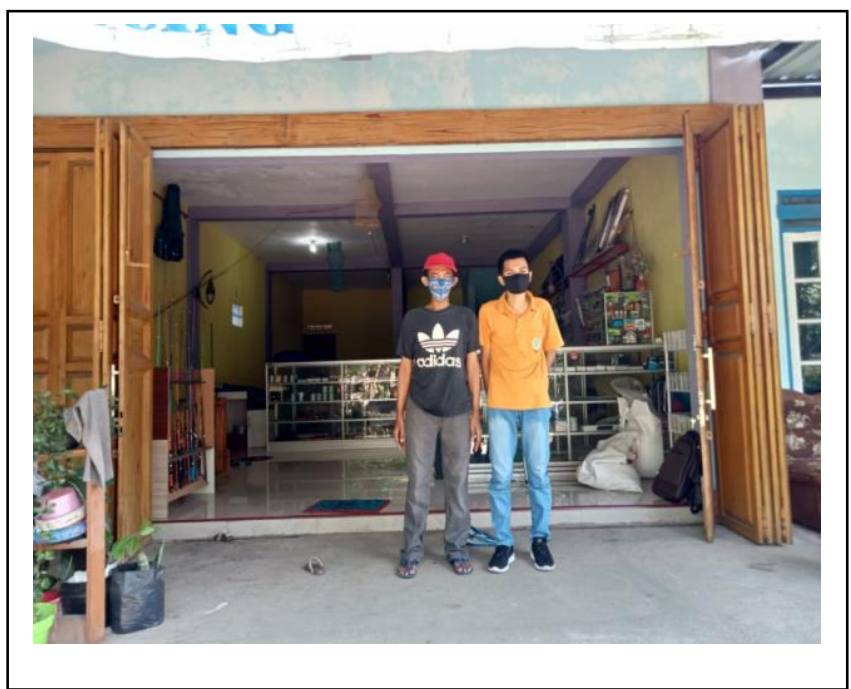

Fig. 10. ( Foto Dengan Owner Muara Pancing )

\section{Kesimpulan}

Kesimpulan yang didapat dalam kerja nyata adalah:

a. Pembuatan website dengan wordpress.

b. Dihasilkan website instansi yang berisi tampilan produk dari Muara Pancing.

a. Pembuatan website dengan wordpress.

b. Dihasilkan website instansi yang berisi tampilan produk dari Muara Pancing.

\section{Daftar Pustaka}

[1] https://www.domainesia.com/.(2020, 25 April). Mutiara Aulia,Panduan Login Cpanel. Diakses pada 26 Maret 2021, dari, https://www.domainesia.com/panduan/cara-login-cpanel/

[2] https://www.niagahoster.co.id/. (2018, 26 Oktober). https://www.niagahoster.co.id/. (2018, 26 Oktober). NiagaHoster,Apa Itu WordPress? Pengertian WordPress dan Manfaatnya. Diakses pada 26 Maret 2021 dari, https://www.niagahoster.co.id/blog/apa-itu-wordpress/

[3] https://www.diadona.id/.(2020, 8 Juli).Novi Hardita Larasati,Pengertian Web Browser dan Contohnya Menurut Para Ahli. Diakses pada 26 Maret 2021, dari,https://www.diadona.id/gadget/pengertian-web-browser-dan-contohnya-menurut-para-ahli-200708u.html

[4] https://saintif.com/. (2020). Saintif,Implementasi - Arti,Pengertian, dan Penjelasannya. Diakses pada 26 Maret 2021, dari,https://saintif.com/implementasi-adalah/

[5] https://review.bukalapak.com/. (18 Juni 2019). Wahyu Kurniawan,3 Jenis Reel Pancing yang Biasa Dipakai Pemancing. Diakses pada 28 Maret 2021 dari, https://review.bukalapak.com/hobbies/3-jenis-reel-pancing-yang-biasa-dipakai-pemancing67002/ 